\begin{tabular}{|c|l|}
\hline Title & Chemistry and electrical properties of surfaces of GaN and GaN/A IGaN heterostructures \\
\hline Author(s) & Hashizume, Tamotsu; Ootomo, Shinya; Oyama, Susumu; Konishi, Masanobu; Hasegawa, Hideki \\
\hline Citation & $\begin{array}{l}\text { Journal of Vacuum Science \& Technology B: Microelectronics and Nanometer Structures, 19(4), 1675-1681 } \\
\text { https:/doi.org/10.1116/1.1383078 }\end{array}$ \\
\hline Issue Date & 2001-07 \\
\hline Doc URL & http:/hdl.handle.net/2115/5806 \\
\hline Type & article \\
\hline File Information & JV STB19-4.pdf \\
\hline
\end{tabular}

Instructions for use 


\title{
Chemistry and electrical properties of surfaces of GaN and GaN/AIGaN heterostructures
}

\author{
Tamotsu Hashizume, ${ }^{\text {a) }}$ Shinya Ootomo, Susumu Oyama, Masanobu Konishi, \\ and Hideki Hasegawa \\ Research Center for Integrated Quantum Electronics (RCIQE), Hokkaido University, \\ Sapporo, 060-8628, Japan
}

(Received 9 January 2001; accepted 7 May 2001)

\begin{abstract}
Chemical and electrical properties of the surfaces of $\mathrm{GaN}$ and GaN/AlGaN heterostructures were systematically investigated by x-ray photoelectron spectroscopy (XPS), capacitance-voltage, and current-voltage measurements. From in situ XPS study, relatively smaller band bending of $0.6 \mathrm{eV}$ was seen at the $\mathrm{GaN}(2 \times 2)$ surface grown by radio frequency-assisted molecular beam epitaxy on the metalorganic vapor phase epitaxy GaN template. After exposing the sample surface to air, strong band bending took place at the surface. The surface treatment in $\mathrm{NH}_{4} \mathrm{OH}$ solution and $\mathrm{N}_{2}$ plasma was found to reduce the surface Fermi level pinning. Surface passivation process of GaN utilizing $\mathrm{SiN}_{x}$ film by electron-cyclotron-resonance assisted plasma chemical vapor deposition (ECR-CVD) achieved low interface state density, $2 \times 10^{11} \mathrm{~cm}^{-2} \mathrm{eV}^{-1}$. No pronounced stress remained at the $\mathrm{SiN}_{x} / \mathrm{GaN}$ interface, which was confirmed by Raman spectroscopy. The present $\mathrm{NH}_{4} \mathrm{OH} / \mathrm{ECR}-\mathrm{N}_{2}$ plasma treatment was also found to be effective in realizing well-ordered and nearly oxide-free surface of a GaN/AlGaN heterostructure. The subsequent passivation process using the ECR-CVD $\mathrm{SiN}_{x}$ film enhanced the drain current in the gateless GaN/AlGaN high electron mobility transistor. A surface passivation process utilizing an ultrathin Al-oxide layer reduced leakage current and improved gate controllability of two-dimensional electron gas in the Schottky gate contact fabricated on the GaN/AlGaN heterostructures. (C) 2001 American Vacuum Society.
\end{abstract}

[DOI: 10.1116/1.1383078]

\section{INTRODUCTION}

$\mathrm{GaN}$ and related heterostructures are now well established as materials for the production of high-power/high-frequency devices such as high-electron mobility transistors (HEMTs) and heterojunction bipolar transistors. These are key devices for the next-generation wireless communication systems, e.g., International Mobile Telecommunications-2000 (IMT2000), with ultrahigh speed and large-volume performance. Reproducibility of the device fabrication process and reliability of the device operation are indispensable for realization of high-performance wireless systems. In fact, surfacetrap related effects have been reported very recently for GaN/AlGaN HEMT devices, namely a significant frequencydependent collapse or the so-called "direct current (dc)-toradio frequency (rf) dispersion" in drain current. ${ }^{1,2}$ Due to the high doping and the degradation of the crystalline quality of an AlGaN layer with a relatively higher $\mathrm{Al}$ content, poor Schottky contact properties, especially large leakage current, were often observed in GaN/AlGaN HEMT devices. This significantly affects the noise performance of HEMT devices. ${ }^{3}$ Thus, understanding and controlling surface properties of $\mathrm{GaN}$ and GaN-based heterostructures is of the utmost importance for their reliable performance with successful surface passivation.

Chemical and electronic properties of clean $\mathrm{GaN}$ surfaces and metal/GaN interfaces processed in an ultrahigh vacuum (UHV) environment have been investigated by several

${ }^{\text {a)} E l e c t r o n i c ~ m a i l: ~ h a s h i @ r c i q e . h o k u d a i . a c . j p ~}$ groups. ${ }^{4-6}$ However, there are a few reports on the processed GaN surfaces such as chemically treated surfaces, plasmatreated surfaces, etc., and on the surfaces of GaN/AlGaN heterostructures, in spite of the fact that the understanding of these surfaces is necessary for the development of actual device fabrication process. For the final stage of surface passivation, the use of thick insulating films is indispensable. In this regard, several studies on insulator-semiconductor (IS) structures using $\mathrm{GaN}$ have been performed. Pioneering works on the GaN IS structures using deposited insulating

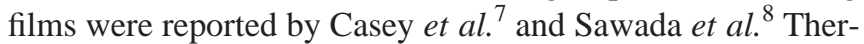
rien et al. ${ }^{9}$ reported a remote plasma process including separate plasma oxidation of $\mathrm{GaN}$ and deposition of thick $\mathrm{SiO}_{2}$ film. Hong et al. ${ }^{10}$ have very recently demonstrated the $\mathrm{Ga}_{2} \mathrm{O}_{3}\left(\mathrm{Gd}_{2} \mathrm{O}_{3}\right) / \mathrm{GaN}$ system with low interface state density. For the GaN/AlGaN structures, Green et al. ${ }^{2}$ have demonstrated that the use of a $\mathrm{Si}_{3} \mathrm{~N}_{4}$ passivation layer improved rf performance of a GaN/AlGaN HEMT, and Kahn and co-workers ${ }^{11,12}$ recently reported the fabrication of the metal-oxide-semiconductor GaN/AlGaN HEMT and its potential of high dc and microwave performance. However, interface properties of GaN and AlGaN IS structures are not fully understood and surface passivation processes of $\mathrm{GaN}$ and GaN/AlGaN heterostructures are not well optimized. Furthermore, in situ characterization of epitaxially grown surfaces is desirable for improving optical and electronic properties of GaN-based heterointerfaces.

In this article, we present a systematic investigation on chemical and electrical properties of surfaces of $\mathrm{GaN}$ and 


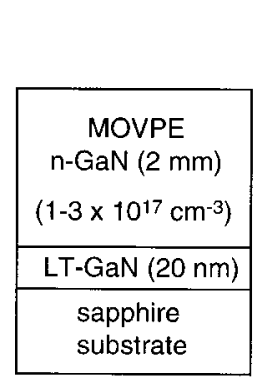

(a)

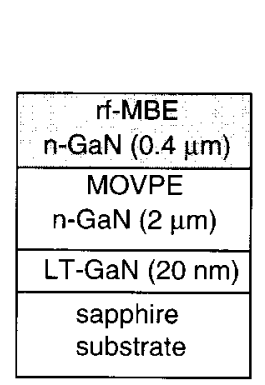

(b)

\begin{tabular}{|c|}
\hline$x_{A l}=0.25$ \\
\hline i-AlGaN $(3 \mathrm{~nm})$ \\
\hline $\begin{array}{c}\text { n-AIGaN }(25 \mathrm{~nm}) \\
2 \times 10^{18} \mathrm{~cm}^{-3} \\
\end{array}$ \\
\hline $\mathrm{i}-\mathrm{AlGaN}(3 \mathrm{~nm})$ \\
\hline $\mathrm{i}-\mathrm{GaN}(0.5 \mu \mathrm{m})$ \\
\hline i-AlGaN $(0.1 \mu \mathrm{m})$ \\
\hline $\mathrm{i}-\mathrm{GaN}(0.2 \mu \mathrm{m})$ \\
\hline $\begin{array}{l}\text { sapphire } \\
\text { substrate }\end{array}$ \\
\hline
\end{tabular}

(c)
FIG. 1. Schematic illustrations of GaN and GaN/AlGaN sample structures: (a) MOVPE $n$-GaN, (b) rf-MBE $n$-GaN, and (c) MOVPE GaN/AlGaN heterostructure.

GaN/AlGaN heterostructures for the optimization of a surface passivation process. Homoepitaxial GaN $(2 \times 2)$ surface grown by molecular beam epitaxy (MBE), chemically treated surface, and plasma treated surface were characterized by x-ray photoelectron spectroscopy (XPS). Electrical properties of the surfaces of $\mathrm{GaN}$ and GaN/AlGaN heterostructures with surface passivation were evaluated by capacitance-voltage $(C-V)$ and current-voltage $(I-V)$ methods.

\section{EXPERIMENT}

\section{A. GaN and GaN/AIGaN sample structures}

Figure 1 shows schematic illustrations of $\mathrm{GaN}$ and GaN/AlGaN sample structures. High-quality epitaxial GaN wafers grown by metalorganic vapor phase epitaxy (MOVPE) were supplied by Hitachi Cable Ltd. A buffer $\mathrm{GaN}$ layer $(\mathrm{LT}-\mathrm{GaN})$ was grown on a sapphire substrate at low temperatures $\left(500-550^{\circ} \mathrm{C}\right)$ followed by the growth of $\mathrm{Si}$-doped $\mathrm{GaN}$ layer at $1000^{\circ} \mathrm{C}$. Typical values of electron concentration and mobility of the Si-doped layer at room temperature (RT) is $2 \times 10^{17} \mathrm{~cm}^{-3}$ and $500 \mathrm{~cm}^{2} / \mathrm{V} \mathrm{s}$, respectively.

As a clean reference GaN surface, a homoepitaxial GaN layer was grown by the rf-radical assisted molecular beam epitaxy (rf-MBE) on MOVPE GaN template, as shown in Fig. 1(b). The substrate temperature was $650^{\circ} \mathrm{C}$. The nitrogen radical beam was produced with rf power of $200 \mathrm{~W}$ and nitrogen gas flow ratio of $2.5 \mathrm{sccm}$ (corresponding to 5 $\times 10^{-5}$ Torr). The growth rate was about $0.1 \mu \mathrm{m} / \mathrm{h}$. Streak reflection high-energy electron diffraction pattern with (2 $\times 2$ ) reconstruction was maintained during the growth, indicating that the grown layer had the Ga-terminated surface. $^{13,14}$ The full width at half maximum of the $\mathrm{x}$-ray rocking curve from the homoepitaxial $\mathrm{GaN}$ layer became the same as that of the MOVPE GaN.

The heterostructure sample consisting of $\mathrm{GaN}$ and $\mathrm{Al}_{0.25} \mathrm{Ga}_{0.75} \mathrm{~N}$ layers grown by MOVPE, as shown in Fig. 1(c), was also supplied by Hitachi Cable Ltd. Typical values of the electron concentration and mobility of the heterostructure sample at RT were $1.5 \times 10^{13} \mathrm{~cm}^{-2}$ and $1300 \mathrm{~cm}^{2} / \mathrm{V} \mathrm{s}$, respectively, comparable to those reported in the literature. In addition, the sample showed clear Shuvnikov-de Haas oscillation in magnetoresistance characteristics at $2 \mathrm{~K}$, and the electron concentration determined from the Landau plots of the oscillation was in good agreement with the value obtained by the Hall measurement at the same temperature. These results clearly indicated the existence of twodimensional electron gas (2DEG) at the GaN/AlGaN heterointerface.

\section{B. Surface passivation process}

In view of actual device fabrication process, a surface passivation process started from a simple wet treatment in organic solvents at $\mathrm{RT}$ and in an $\mathrm{NH}_{4} \mathrm{OH}$ solution at $50^{\circ} \mathrm{C}$ for 5-10 min. Then GaN and GaN/AlGaN surfaces were processed in electron-cyclotron-resonance (ECR) excited $\mathrm{N}_{2}$ plasma at $300^{\circ} \mathrm{C}$ for $1-5 \mathrm{~min}$ with microwave $(2.75 \mathrm{GHz})$ power of $50 \mathrm{~W}$. Final passivation was performed by the deposition of $\mathrm{SiN}_{x}$ film on the sample surface at $280^{\circ} \mathrm{C}$ by ECR assisted plasma chemical vapor deposition (ECRCVD) using $\mathrm{SiH}_{4}$ and $\mathrm{N}_{2}$. We obtained a diffractive index value of 1.98 for the deposited $\mathrm{SiN}_{x}$ film. Thickness of the deposited film ranged from 40 to $60 \mathrm{~nm}$.

As an ohmic contact for $I-V$ and $C-V$ measurements, a $\mathrm{Ti} / \mathrm{Al} / \mathrm{Ti} / \mathrm{Au}$ contact ring was deposited on the surfaces of $\mathrm{GaN}$ and GaN/AlGaN followed by the annealing at $600^{\circ} \mathrm{C}$ for $2 \mathrm{~min}$ in $\mathrm{N}_{2}$ ambient. The $\mathrm{Pt} / \mathrm{Au}$ contact and the $\mathrm{Al}$ contact with a diameter of $500 \mu \mathrm{m}$ were used for the Schottky and metal-insulater-semiconductor (MIS) structures, respectively.

\section{Characterization methods}

The surface chemical properties of $\mathrm{GaN}$ and $\mathrm{GaN} / \mathrm{AlGaN}$ samples were characterized by XPS. The XPS measurement system (Perkin Elmer PHI 1600C) consists of a spherical capacitor analyzer and a monochromated $\mathrm{Al} K \alpha$ x-ray source $(h v=1486.6 \mathrm{eV})$. The XPS system is connected to the MBE growth chamber and ECR-CVD chamber through the UHV transfer system with a base pressure of $2 \times 10^{-10}$ Torr, thereby in situ XPS characterization of the MBE-grown or plasma-processed surfaces is available. The binding energies of the spectra were carefully calibrated through separate measurements of $\mathrm{Cu} 2 p_{3 / 2}, \mathrm{Ag} 3 d_{5 / 2}$, and $\mathrm{Au} 4 f_{7 / 2}$ peak positions. Atomic force microscope (AFM) observation of $\mathrm{GaN}$ surfaces after various types of surface treatments was carried out using a Nanoscope II (Digital Instruments). $C-V$ curves were measured at RT using a HP 4192A LF impedance analyzer. In order to avoid the impact of the series resistance of the epitaxial $\mathrm{GaN}$ and $\mathrm{AlGaN}$ layers on the $C-V$ measurements, characterization took place at a frequency of $100 \mathrm{kHz}$. $C-V$ curves were recorded at a sweep rate of $100 \mathrm{mV} / \mathrm{s}$.

\section{RESULTS AND DISCUSSION}

\section{A. XPS and AFM characterization of GaN surfaces}

Figure 2 shows $\mathrm{Ga} 3 d$ and $\mathrm{N} 1 s$ in situ spectra obtained from the rf-MBE grown $\mathrm{GaN}(2 \times 2)$ surface and ex situ spectra from the air-exposed surface. After exposing the 


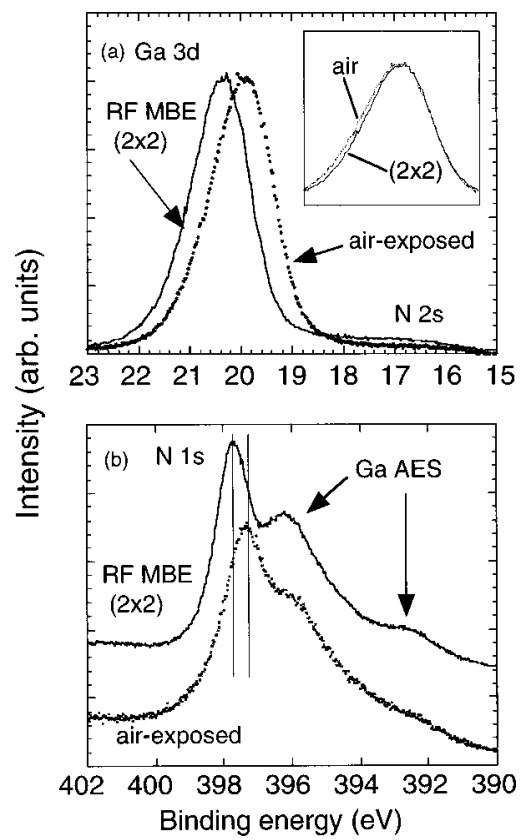

FIG. 2. XPS Ga $3 d$ and $\mathrm{N} 1 s$ in situ spectra obtained from the rf-MBE grown $\mathrm{GaN}(2 \times 2)$ surface and $e x$ situ spectra from the air-exposed surface.

sample to air, noticeable peak shift toward lower binding energies was seen in both Ga $3 d$ and $\mathrm{N} 1 s$ spectra. In addition, an asymmetric feature of the Ga $3 d$ level with a shoulder at higher binding energies, as shown in the inset of Fig. 2(a), and the narrower energy separation between the $\mathrm{N} 1 s$ and Ga Auger electron spectroscopy (AES) peaks [Fig. 2(b)] were observed at the air-exposed surface. This feature as well as a high intensity of the $\mathrm{O} 1 \mathrm{~s}$ level indicated that an air-exposed $\mathrm{GaN}$ surface was covered with a natural oxide layer including a Ga-oxide component. The rigorous deconvolution of the Ga $3 d$ and $\mathrm{N} 1 s$ spectra led to the conclusion that the air-exposed surface exhibits Ga-rich phase and that $\mathrm{Ga}_{2} \mathrm{O}_{3}$ is the dominant component in the surface natural oxide.

Figure 3(a) shows the O $1 \mathrm{~s}$ spectra of the MOVPE sample after the air exposure and the $\mathrm{NH}_{4} \mathrm{OH} / \mathrm{N}_{2}$ plasma treatments. Two peaks corresponding to the $\mathrm{O}-\mathrm{H}$ bond ${ }^{15,16}$ and the $\mathrm{Ga}_{2} \mathrm{O}_{3}$ bond ${ }^{17,18}$ appeared at the air-exposed surface. After the $\mathrm{NH}_{4} \mathrm{OH} / \mathrm{N}_{2}$ plasma treatments, drastic reduction of the $\mathrm{O} 1 \mathrm{~s}$ peak was observed. In addition, this process realized a shoulderless feature of the Ga $3 d$ level and clear separation of energy peaks between the N $1 s$ and Ga AES signals. The effect of the surface treatments on the reduction of natural oxide layer on the GaN surface was summarized in Fig. 3(b), in terms of change in the XPS integrated intensity of the $\mathrm{O} 1 s$ level normalized by the $\mathrm{N} 1 s$ level. As mentioned earlier, a high intensity of the $\mathrm{O} 1 s$ peak appeared on the air-exposed surface. After the $\mathrm{NH}_{4} \mathrm{OH}$ treatment, significant decrease of the oxide components was observed. Further reduction of oxide components was achieved by the surface treatment in the ECR $-\mathrm{N}_{2}$ plasma. The plasma process was also effective in removing surface contamination. The Ga $3 d / \mathrm{N} 1 s$ intensity ratio became close to the stoichiometric
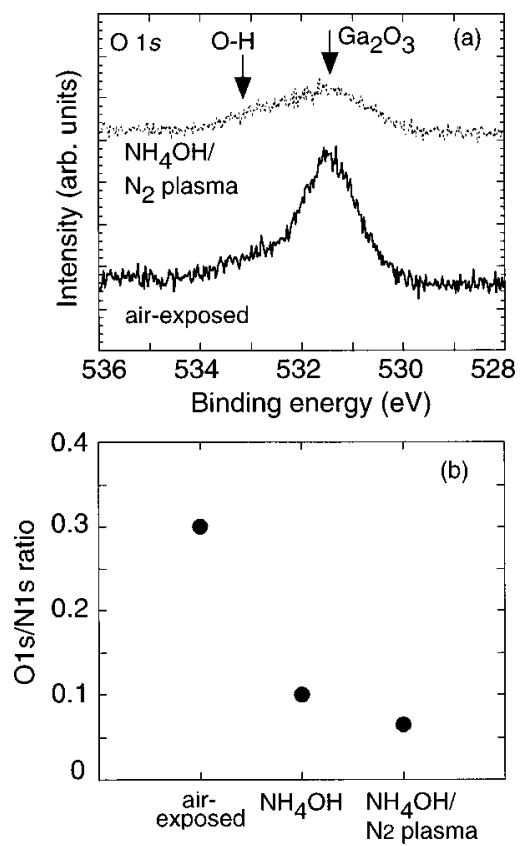

FIG. 3. (a) O $1 s$ spectra of the MOVPE sample after the air exposure and the $\mathrm{NH}_{4} \mathrm{OH} / \mathrm{N}_{2}$ plasma treatments, and (b) change in the XPS integrated intensity of the $\mathrm{O} 1 s$ level normalized by the $\mathrm{N} 1 s$ level.

value after the series of surface passivation process. This is due to the removal of natural gallium oxide layer, which made the surface nearly oxide-free.

Figure 4 shows the positions of surface Fermi level $\left(E_{f_{s}}\right)$ for various $\mathrm{GaN}$ surfaces. The value of $E_{f s}$ was determined by the peak position of the Ga $3 d$ core level where the value of $17.8 \mathrm{eV}$ corresponds to the separation between the $\mathrm{Ga} 3 d$ level and the valence band maximum, $E_{v} \cdot{ }^{4,5,19,20}$ We confirmed that the $E_{f s}$ positions estimated by the $\mathrm{N} 1 s$ core level and the valence band spectra were identical to the results shown in Fig. 4. Note that the data for the $\mathrm{N}_{2}$-plasma treated surface and $\mathrm{SiN}_{x}(2 \mathrm{~nm})$-deposited surfaces were obtained by in situ XPS measurements.

The fresh MBE-grown $(2 \times 2)$ surface showed $E_{f s}$ to lie at $2.7 \mathrm{eV}$ above $E_{v}$, indicating the upward band bending of $0.6 \mathrm{eV}$. It is well known that the nitrogen-ion bombardment or the Ga deposition followed by the UHV annealing

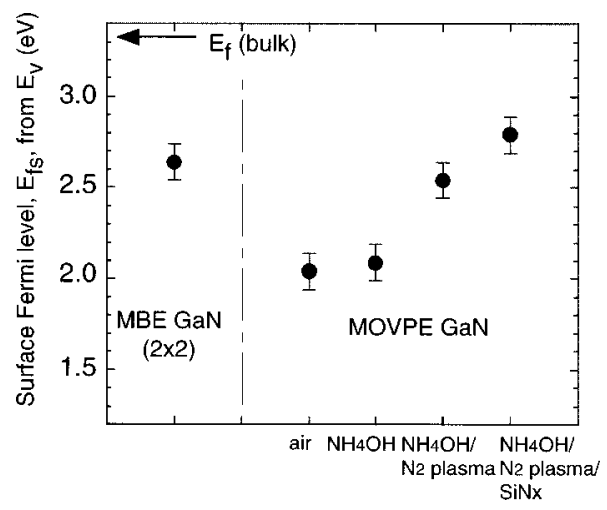

FIG. 4. Positions of surface Fermi level $\left(E_{f s}\right)$ for various GaN surfaces. 


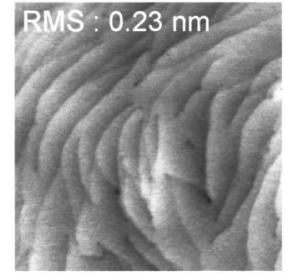

(a) $\mathrm{NH}_{4} \mathrm{OH}$

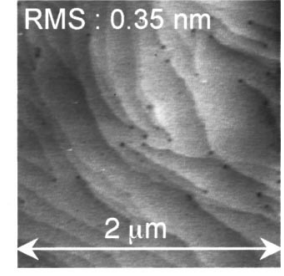

(b) $\mathrm{NH}_{4} \mathrm{OH} / \mathrm{N}_{2}$ plasma
FIG. 5. AFM images of the GaN surfaces after the $\mathrm{NH}_{4} \mathrm{OH}$ and $\mathrm{ECR}$ $\mathrm{N}_{2}$-plasma treatments.

at $800-900{ }^{\circ} \mathrm{C}$ realized clean $(1 \times 1)$-ordered $\mathrm{GaN}$ surfaces. ${ }^{4,5,21}$ These clean $(1 \times 1)$ surfaces showed relatively strong band bending. Bermudez $\mathrm{z}^{4,6}$ and $\mathrm{Wu}$ and $\mathrm{Kahn}^{5}$ concluded that the band bending of $0.8-0.9 \mathrm{eV}$ existed at such $(1 \times 1)$ surfaces. Stronger bending of about $2.1 \mathrm{eV}$ was reported by Dhesi and co-workers. ${ }^{22}$ In comparison, our in situ XPS study showed smaller band bending on the MBE-grown $(2 \times 2)$ surface. Theoretical calculations ${ }^{23,24}$ predicted that the $(2 \times 2)$ reconstruction is the most stable structure for the (0001) Ga-terminated surface.

The position of $E_{f s}$ was found at $E v+2.0 \mathrm{eV}$ for the airexposed MOVPE GaN sample, indicating relatively strong band bending of 1.3-1.4 eV. Wu and $\mathrm{Kahn}^{5}$ and Wolter et $a .^{25}$ reported similar $E_{f s}$ position at the air-exposed MOVPE GaN surface. The surface included natural oxide and contamination, and showed a nonstoichiometric (Garich) feature. This probably causes the strong band bending. The surface band bending is sensitive to contamination, disorder, and defects at the surface since the Fermi level position is governed by the balance between the surface charge and the ionized donors in the depletion region. In contrast to these results, Bermudez ${ }^{4}$ concluded that smaller band bending of $0.4 \mathrm{eV}$ appeared at the oxidized and contaminated $\mathrm{GaN}$ surface. The reason for the discrepancy is not clear yet.

After the surface treatment in the $\mathrm{NH}_{4} \mathrm{OH}$ solution at $50^{\circ} \mathrm{C}$ for $10 \mathrm{~min}$, the surface natural oxide was reduced, as shown in Fig. 3. However, the $E_{f s}$ position did not change from the position at the air-exposed surface. The following surface process in ECR-excited $\mathrm{N}_{2}$ plasma was found to have an effect on the reduction of the surface band bending, as shown in Fig. 4. The $E_{f s}$ position moved up to $0.4-0.5 \mathrm{eV}$ above the position of the air-exposed sample. The depletion of $\mathrm{N}$ atoms was found at the air-exposed sample, leading to the vague separation of the $\mathrm{N} 1 s$ and Ga AES levels, as seen in the bottom trace in Fig. 2(b). The Ga-to-N ratio was 1.12 at the air-exposed surface, consistent with the result of $\mathrm{Wu}$ and Kahn. ${ }^{5}$ The ECR- $\mathrm{N}_{2}$ plasma treatment seems to partially recover or terminate $\mathrm{N}$-deficiency related defects. The subsequent deposition of $\mathrm{SiN}_{x}$ film by ECR-CVD realized further upward movement of surface Fermi level, indicating pronounced passivation effect.

Typical AFM images of the GaN surfaces after the $\mathrm{NH}_{4} \mathrm{OH}$ and ECR $\mathrm{N}_{2}$-plasma treatments were shown in Fig. 5. The as-grown MOVPE GaN exhibited smooth surface with a root-mean-square $(\mathrm{rms})$ value of $0.23 \mathrm{~nm}$. The

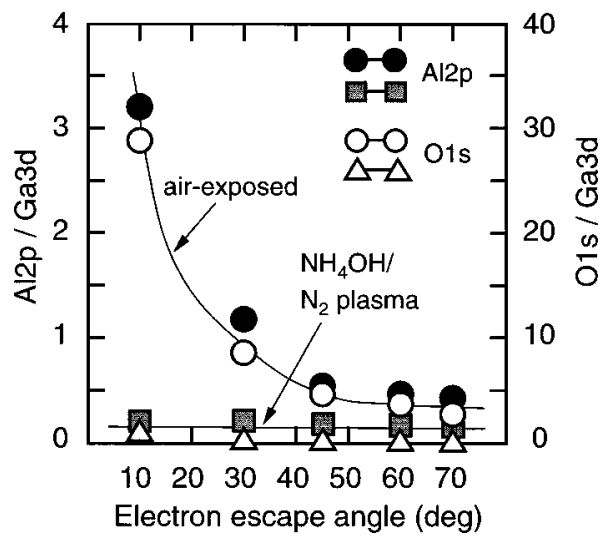

FIG. 6. Integrated XPS intensity ratios of $\mathrm{Al} 2 p / \mathrm{Ga} 3 d$ and $\mathrm{O} 1 s / \mathrm{Ga} 3 d$ obtained from the GaN/AlGaN heterostructure surface as a function of the electron escape angle.

$\mathrm{NH}_{4} \mathrm{OH}$ treatment completely maintained the surface smoothness showing the characteristic feature dominated by monolayer steps. The rms value comparable to that of the as-grown sample was obtained even after the plasma treatment process, as shown in Fig. 5(b).

\section{B. XPS characterization of GaN/AIGaN surface}

The air-exposed surface of the MOVPE GaN/AlGaN heterostructure sample exhibited highly nonstoichiometric phase with large amounts of natural oxide. ${ }^{26}$ Figure 6 shows the integrated XPS intensity ratios of $\mathrm{Al} 2 p / \mathrm{Ga} 3 d$ and $\mathrm{O}$ $1 s / \mathrm{Ga} 3 d$ as a function of the electron escape angle. The air-exposed sample exhibited complicated composition distribution in depth. In particular, steep increase of $\mathrm{Al} 2 p$ and $\mathrm{O} 1 s$ intensities at shallower escape angles indicated that the Al-oxide component is dominant on the topmost surface. The Al $2 p$ core-level exhibited broad spectra with a peak binding energy very close to that of $\mathrm{Al}_{2} \mathrm{O}_{3}$, and asymmetric spectra with a shoulder including the $\mathrm{Ga}_{2} \mathrm{O}_{3}$ component appeared in the Ga $3 d$ core level. ${ }^{26}$ Such a natural oxide layer can be removed after the $\mathrm{NH}_{4} \mathrm{OH} / \mathrm{ECR}-\mathrm{N}_{2}$ plasma treatments, as indicated by the shaded squares and open triangles in Fig. 6 . A significant reduction of the $\mathrm{O} 1 s$ intensity is seen, and the composition does not vary with depth from this surface. In fact, the surface treatment led to symmetric features in both Al $2 p$ and Ga $3 d$ spectra where the peak positions of these spectra were very close to those of the $\mathrm{Al}-\mathrm{N}$ bond and the $\mathrm{Ga}-\mathrm{N}$ bond. From the relative XPS sensitivity factors, the Al composition was calculated to be 0.23 , in reasonably agreement with the value of 0.25 obtained from the separate $\mathrm{x}$-ray diffraction measurement. Thus, the present $\mathrm{NH}_{4} \mathrm{OH} / \mathrm{ECR}-\mathrm{N}_{2}$ plasma treatment was found to be effective in realizing well ordered and nearly oxide-free surface of a GaN/AlGaN heterostructure.

In order to improve Schottky gate properties on the GaN/AlGaN HEMT structure, a passivation approach was attempted. The process started from the formation of ultrathin $(1 \mathrm{~nm}) \mathrm{Al}$ layer on the $\mathrm{NH}_{4} \mathrm{OH}$-treated GaN/AlGaN surface at RT using a $K$ cell in the MBE chamber. Then the 


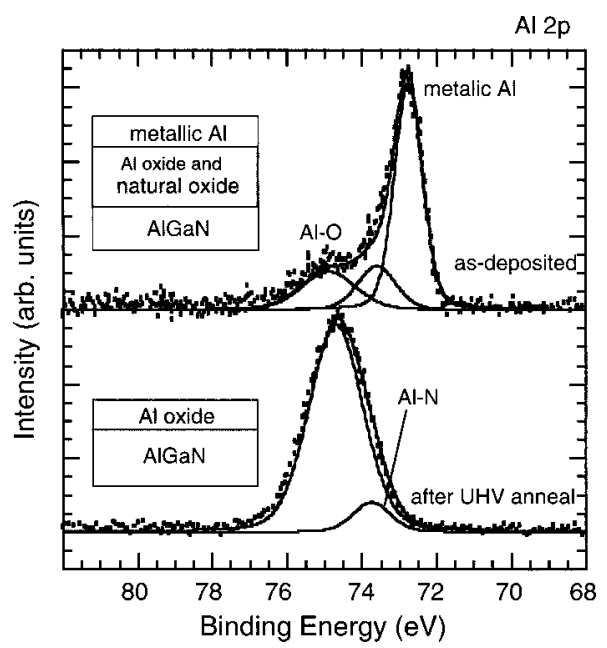

FIG. 7. In situ XPS Al $2 p$ spectra of the $\mathrm{NH}_{4} \mathrm{OH}$-treated GaN/AlGaN/Al sample prepared in the MBE chamber (a) before and (b) after the UHV anneal at $700{ }^{\circ} \mathrm{C}$ for $10 \mathrm{~min}$.

sample was annealed at $700{ }^{\circ} \mathrm{C}$ for $10 \mathrm{~min}$ in an UHV environment (base pressure: $2 \times 10^{-10}$ Torr). The basic idea of this process is to convert the natural oxide on the AlGaN surface to the $\mathrm{Al}$ oxide $\left(\mathrm{Al}_{2} \mathrm{O}_{3}\right)$ by use of the reduction reaction of natural oxide with active metallic $\mathrm{Al}$ driven by the large heat of formation of $\mathrm{Al}_{2} \mathrm{O}_{3}$.

Figure 7 shows in situ XPS Al $2 p$ spectra of the $\mathrm{NH}_{4} \mathrm{OH}$-treated $\mathrm{GaN} / \mathrm{AlGaN} / \mathrm{Al}$ sample prepared in the MBE chamber. In spite of the fact that $\mathrm{Al}$ was evaporated at room temperature in an $\mathrm{UHV}$ environment, the $\mathrm{Al} 2 p$ spectra clearly included an oxide component $\left(\mathrm{Al}_{2} \mathrm{O}_{3}\right)$ in addition to the metallic $\mathrm{Al}$ and the $\mathrm{Al}-\mathrm{N}$ bonds. Judging from the escape-angle dependence of the $\mathrm{Al} 2 p$ and $\mathrm{O} 1 s$ peak intensities (not shown here), an interfacial layer resulting from the reaction between $\mathrm{Al}$ and natural oxide was formed at the $\mathrm{Al} / \mathrm{AlGaN}$ interface. Such a layer structure $(\mathrm{Al}+$ oxides $)$ was found to convert to the $\mathrm{Al}_{2} \mathrm{O}_{3}$ layer completely after the UHV thermal annealing at $700^{\circ} \mathrm{C}$ for $10 \mathrm{~min}$, as shown in the bottom trace in Fig. 7. Note that the Al-N peak originated from the $\mathrm{AlGaN}$ layer underneath the topmost $\mathrm{Al}$ oxide layer. Thus the present UHV process allows us to form the $\mathrm{GaN} / \mathrm{AlGaN} /$ ultrathin $\mathrm{Al}$ oxide passivation structure.

\section{Electrical properties of passivated $\mathrm{GaN}$ and GaN/AIGaN surfaces}

Electrical properties of the passivated GaN surface were investigated using a MIS structure with a thick $(40-60 \mathrm{~nm})$ $\mathrm{SiN}_{x}$ film. Figure 8 shows distributions of interface state density $\left(D_{\text {it }}\right)$ of the fabricated $\mathrm{SiN}_{x} / n$-GaN structures. For comparison, the $D_{\text {it }}$ distribution of the $\mathrm{SiO}_{2} / n-\mathrm{GaN}$ interface was plotted. The $D_{\text {it }}$ distributions were calculated by applying the Terman method to the measured $C-V$ curves at room temperature. Typical $C-V$ data of the $\mathrm{SiN}_{x} / n-\mathrm{GaN}$ sample with the $\mathrm{NH}_{4} \mathrm{OH} / \mathrm{ECR}-\mathrm{N}_{2}$ plasma treatment were plotted in the inset of Fig. 8. Also shown is the calculated curve based on the accumulation, depletion and inversion behavior for the MIS structure. For calculation, an effective electron mass

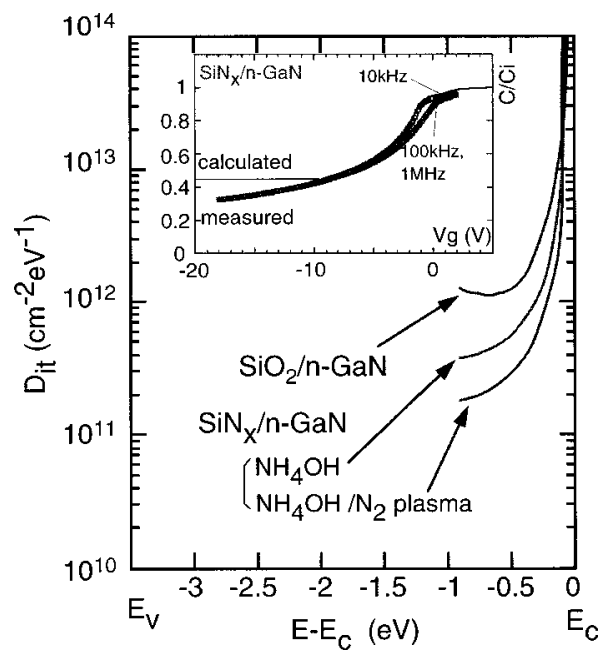

FIG. 8. Distributions of interface state density $\left(D_{\mathrm{it}}\right)$ of the fabricated $n$-GaN MIS structures. Typical $C-V$ data obtained from the $\mathrm{NH}_{4} \mathrm{OH} / \mathrm{ECR}-\mathrm{N}_{2}$ plasma passivated sample were plotted in the inset.

of $0.22 m_{0}$, an effective hole mass of $0.8 m_{0}$, a dielectric constant of 9.5 and an energy gap of $3.39 \mathrm{eV}$ were used for $\mathrm{GaN}$ at room temperature.

In comparison with the $\mathrm{SiO}_{2} / n-\mathrm{GaN}$ interface, the $\mathrm{SiN}_{x} / \mathrm{GaN}$ structures showed relatively low density of interface states. The measured $C-V$ curves were very close to the calculated ones, and small hysteresis and frequency dispersion were achieved. Furthermore, clear deep depletion behavior was observed at room temperature, as shown in the inset of Fig. 8. This deep depletion feature with no inversion capacitance characteristics is typical of wide-gap semiconductor MIS structures such as $\mathrm{SiO}_{2} / \mathrm{SiC}^{27}$ and $\mathrm{AlN} / \mathrm{SiC}{ }^{28}$ because the generation rate of the minority carriers (holes) is extremely low at room temperature. The $1 / \mathrm{C}^{2}$ characteristics as a function of the applied gate voltage showed good linear behavior, indicating the presence of deep depletion by pronounced band bending. From the slope of the plots, the carrier density of $n$-GaN layer was determined to be 1.7 $\times 10^{17} \mathrm{~cm}^{-3}$, very close to the value of $2.0 \times 10^{17} \mathrm{~cm}^{-3}$ obtained from the Hall measurement. These results indicated that the control of surface potential of $\mathrm{GaN}$ over a remarkably wide range was achieved in the $\mathrm{SiN}_{x} / \mathrm{GaN}$ interface. As shown in Fig. 8, the $\mathrm{NH}_{4} \mathrm{OH} / \mathrm{ECR}-\mathrm{N}_{2}$ plasma passivation process achieved low $D_{\text {it }}$ value of $2 \times 10^{11} \mathrm{~cm}^{-2} \mathrm{eV}^{-1}$. These results were consistent with the reduction of the surface band bending at the passivated GaN surface, as confirmed by XPS analysis (Fig. 4). Furthermore, the Raman spectroscopy study revealed that no stress was found at the present $\mathrm{SiN}_{x} / \mathrm{GaN}$ structure.

Based on these results, the present $\mathrm{NH}_{4} \mathrm{OH} / \mathrm{ECR}-\mathrm{N}_{2}$ plasma passivation followed by the deposition of thick $\mathrm{SiN}_{x}$ film was applied to the surface of GaN/AlGaN heterostructure. Figure 9 shows the $I-V$ characteristics of the gateless GaN/AlGaN HEMT structure with and without surface passivation. The drain to source distance is $8 \mu \mathrm{m}$. Enhancement of drain current was observed for the structure with the surface passivation. Similar effect on the drain current as well 


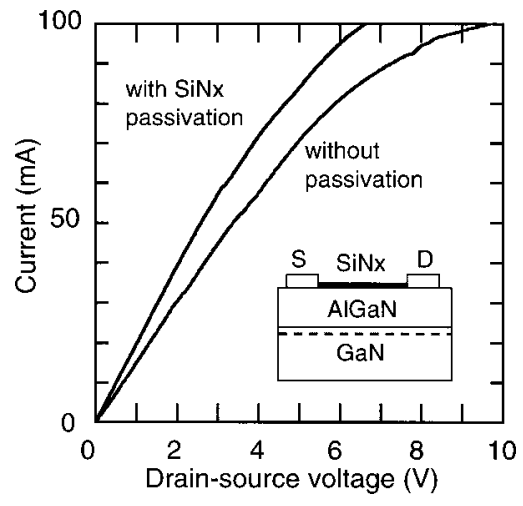

FIG. 9. $I-V$ characteristics of the gateless GaN/AlGaN HEMT structure with and without $\mathrm{SiN}_{x}$ surface passivation.

as the $\mathrm{rf}$ characteristics were demonstrated in the GaN/AlGaN HEMT with the $\mathrm{Si}_{3} \mathrm{~N}_{4}$ passivation layer. ${ }^{2}$ Our detailed XPS study on GaN surface indicated that the reduction of surface band bending by passivation could enhance the 2DEG density at the GaN/AlGaN interface, and that the reduction of surface states could suppress surface-trap related effects.

Finally, a surface passivation approach, as described in Sec. III B, was attempted to improve Schottky gate properties in the GaN/AlGaN HEMT structure. Figure 10 compares $I-V$ characteristics of the Pt/Au Schottky contacts with and without an Al-oxide interface layer fabricated on the $\mathrm{NH}_{4} \mathrm{OH}$-treated surface of GaN/AlGaN heterostructures. In the forward bias region, good linearity of the $\log (I)-V$ relation was obtained for the contact with the Al-oxide interface layer. This contact showed relatively small ideality factor, $n$, of 1.17 , similar to the normal Schottky contact. This means that the insertion of the Al-oxide layer did not disturb current transport based on the thermionic emission process. Significant improvement in the $I-V$ characteristics was seen in the reverse bias region, i.e., the reduction of reverse leakage current in about two orders of magnitude. This seems to be due to the formation of uniform ultrathin Al-oxide layer on the AlGaN surface.

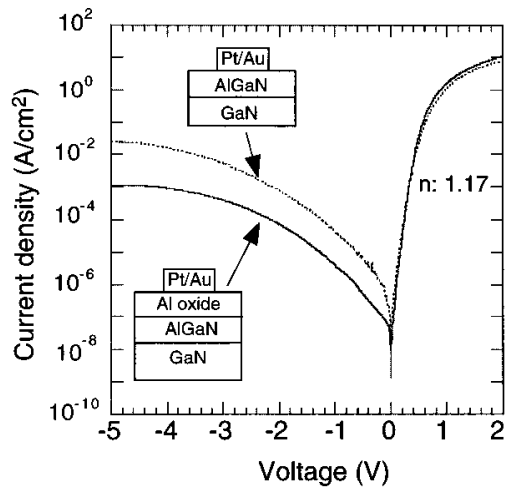

FIG. 10. $I-V$ characteristics of the $\mathrm{Pt} / \mathrm{Au}$ Schottky contacts with and without an Al-oxide interface layer fabricated on the $\mathrm{NH}_{4} \mathrm{OH}$-treated surface of GaN/AlGaN heterostructures.

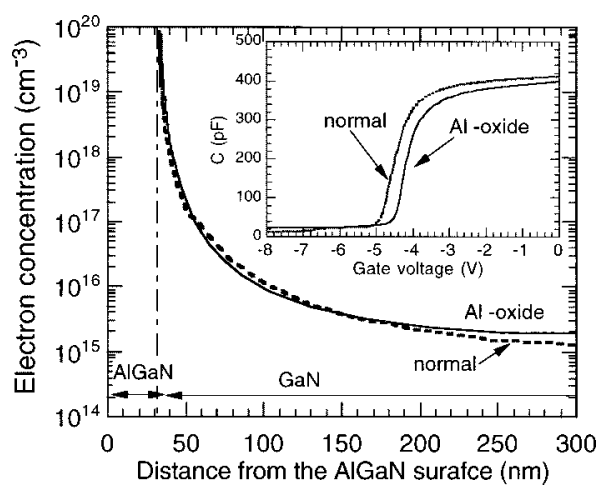

FIG. 11. Profiles of electron concentration near the GaN/AlGaN interface as a function of distance from the top AlGaN surface. The measured $C-V$ curves on the Pt/Au Schottky gates are shown in the inset.

The Schottky gate controllability of 2DEG was evaluated by measuring $C-V$ characteristics. ${ }^{29}$ Figure 11 shows the profiles of electron concentration near the GaN/AlGaN interface as a function of distance from the top AlGaN surface. The measured $C-V$ curves are shown in the inset of Fig. 11. A slight decrease in capacitance at zero bias is probably due to the insertion of the Al-oxide layer. The value of the capacitance change corresponded to the equivalent increase of the thickness of the AlGaN layer to be $1.5 \mathrm{~nm}$. This is very close to nominal thickness of the Al-oxide layer when we assume the dielectric constant, $\epsilon_{s}$, of the Al oxide (e.g., $\epsilon_{s}$ of $\left.\mathrm{Al}_{2} \mathrm{O}_{3}=8.5\right)$ is close to that of $\mathrm{AlGaN}\left(\epsilon_{s}=9.0\right)$. For the Al-oxide inserted contact, the pinch-off voltage is $0.3-0.4 \mathrm{~V}$ smaller than that of the normal contact, and steep onset behavior was seen in the $C-V$ curve.

As shown in the carrier profiles, the high electron concentration was observed at the $\mathrm{AlGaN} / \mathrm{GaN}$ interface, similar to the results reported by Yu et al. ${ }^{30}$ and Manfra et al. ${ }^{31}$ This indicated the existence of 2DEG at the interface. Away from the heterointerface, the electron concentration falls off sharply and then saturates in the profile obtained from the Al-oxide inserted contact. This is consistent with the growth design, as shown in Fig. 1(c). On the other hand, the electron concentration gradually decreases even in the undoped $\mathrm{GaN}$ layer region for the profile obtained by the normal contact, as indicated by the broken line in Fig. 11. Steep increase of the leakage current (Fig. 10) seems to be one of possible reasons for such behavior. These results indicated that a surface passivation structure using an ultrathin $\mathrm{Al}$-oxide layer is effective in improving the Schottky gate control of 2DEG in GaN/AlGaN HEMT structures.

\section{CONCLUSION}

We have investigated chemical and electrical properties of surfaces of $\mathrm{GaN}$ and $\mathrm{GaN} / \mathrm{AlGaN}$ heterostructures for the optimization of a surface passivation process. In situ XPS study revealed that relatively smaller band bending of $0.6 \mathrm{eV}$ existed at the $\mathrm{GaN}(2 \times 2)$ surface grown by $\mathrm{rf}-\mathrm{MBE}$ on the MOVPE GaN template. The air-exposed sample showed strong band bending. The surface treatment in $\mathrm{NH}_{4} \mathrm{OH}$ solution and ECR $\mathrm{N}_{2}$ plasma was found to reduce the surface 
Fermi level pinning. Surface passivation process of GaN utilizing $\mathrm{SiN}_{x}$ film prepared by the ECR-CVD achieved low interface state density, $D_{\text {it }}$ of $2 \times 10^{11} \mathrm{~cm}^{-2} \mathrm{eV}^{-1}$. The present $\mathrm{NH}_{4} \mathrm{OH} / \mathrm{ECR}-\mathrm{N}_{2}$ plasma treatment was also found to be effective in realizing well ordered and nearly oxide-free surface of a GaN/AlGaN heterostructure. The subsequent passivation process using the ECR-CVD $\mathrm{SiN}_{x}$ film enhanced the drain current in the gateless GaN/AlGaN HEMT. A surface passivation process utilizing an ultrathin Al-oxide layer reduced reverse leakage current and improved gate controllability of 2DEG in the Schottky gate contact fabricated on the GaN/AlGaN heterostructure. The present passivation processes are promising for realizing reproducibility of the device fabrication process and reliability of the device operation in GaN-based high-power/high-frequency devices.

\section{ACKNOWLEDGMENTS}

The authors thank M. Kihara of Hitachi Cable Ltd. for the supply of MOVPE GaN and GaN/AlGaN HEMT samples. This work was partly supported by a grant-in-aid for Scientific Research (B) (No. 11555081) and (C) (No. 11650309) from the Ministry of Science, Education, Sports, and Culture, Japan.

\footnotetext{
${ }^{1}$ U. Mishra, presented at the International Workshop on Nitride Semiconductors (IWN2000), 24-27 September 2000, Nagoya.

${ }^{2}$ B. M. Green, K. K. Chu, E. M. Chumbes, J. A. Smart, J. M. Shealy, and

L. F. Eastman, IEEE Electron Device Lett. 21, 268 (2000).

${ }^{3}$ S. L. Rumyantsev et al., J. Appl. Phys. 88, 6726 (2000).

${ }^{4}$ V. M. Bermudez, J. Appl. Phys. 80, 1190 (1996).

${ }^{5}$ C. I. Wu and A. Kahn, J. Vac. Sci. Technol. B 16, 2218 (1998).

${ }^{6}$ V. M. Bermudez, D. D. Koleske, and A. E. Wickenden, Appl. Surf. Sci. 126, 69 (1998).

${ }^{7}$ H. C. Casey, Jr., G. G. Fountain, R. G. Alley, B. P. Keller, and S. P. DenBaars, Appl. Phys. Lett. 68, (1996).

${ }^{8}$ M. Sawada, T. Sawada, Y. Yamagata, K. Imai, H. Kimura, M. Yoshino,
}

K. Iizuka, and H. Tomozawa, J. Cryst. Growth 189/190, 706 (1998).

${ }^{9}$ R. Therrien, G. Lucovsky, and R. Davis, Appl. Surf. Sci. 166, 513 (2000).

${ }^{10}$ M. Hong et al., J. Vac. Sci. Technol. B 18, 1453 (2000).

${ }^{11}$ M. A. Kahn, X. Hu, G. Simin, A. Lunev, J. Yang, R. Gaska, and M. S. Shur, IEEE Electron Device Lett. 21, 63 (2000).

${ }^{12}$ M. A. Kahn, X. Hu, A. Takakji, G. Simin, J. Yang, R. Gaska, and M. S. Shur, Appl. Phys. Lett. 77, 1339 (2000).

${ }^{13}$ P. Hacke, G. Feuillet, H. Okumura, and S. Yoshida, J. Cryst. Growth 175/176, 94 (1997).

${ }^{14}$ A. R. Smith, R. M. Feenstra, D. W. Greve, M.-S. Shin, M. Skowronski, J. Neugebauer, and J. E. Northrup, Appl. Phys. Lett. 72, 2114 (1998).

${ }^{15}$ I. Waki, H. Fujioka, K. Ono, M. Oshima, H. Miki, and A. Fukizawa, Jpn. J. Appl. Phys., Part 1 39, 4451 (2000).

${ }^{16}$ Y.-J. Lin and C.-T. Lee, Appl. Phys. Lett. 77, 3986 (2000).

${ }^{17}$ G. Hollinger, S. Skheyta-Kabbani, and M. Gendry, Phys. Rev. B 49, 11159 (1994).

${ }^{18}$ N. J. Watkins, G. W. Wicks, and Y. Gao, Appl. Phys. Lett. 75, 2602 (1999).

${ }^{19}$ J. R. Waldrop and R. W. Grant, Appl. Phys. Lett. 68, 2879 (1996).

${ }^{20}$ C. I. Wu and A. Kahn, J. Appl. Phys. 86, 3209 (1999).

${ }^{21}$ M. A. Kahn, J. N. Kuznia, D. T. Olson, and R. Kaplan, J. Appl. Phys. 73, 3108 (1993).

${ }^{22}$ S. S. Dhesi, C. B. Stagarescu, K. E. Smith, D. Doppalapudi, R. Singh, and D. Moustakas, Phys. Rev. B 56, 10271 (1997).

${ }^{23}$ K. Rapcewicz, M. B. Nardelli, and J. Bernholc, Phys. Rev. B 56, R12725 (1997).

${ }^{24}$ A. R. Smith, R. M. Feenstra, D. W. Greve, J. Neugebauer, and J. E. Northrup, Phys. Rev. Lett. 79, 3934 (1997).

${ }^{25}$ S. D. Wolter, J. M. DeLucca, S. E. Mohny, R. S. Kern, and C. P. Kuo, Thin Solid Films 371, 153 (2000).

${ }^{26}$ T. Hashizume, S. Ootomo, R. Nakasaki, S. Oyama, and M. Kihara, Appl. Phys. Lett. 76, 2880 (2000).

${ }^{27}$ M. K. Das, J. A. Cooper, Jr., and M. R. Melloch, J. Electron. Mater. 27, 353 (1997).

${ }^{28}$ C.-M. Zetterling, M. Östling, K. Wongchotigul, M. G. Spencer, X. Tang, C. I. Harris, N. Nordell, and S. S. Wong, J. Appl. Phys. 82, 2990 (1997).

${ }^{29}$ O. Ambacher et al., J. Appl. Phys. 85, 3222 (1999).

${ }^{30}$ E. T. Yu, G. J. Sullivan, P. M. Asbeck, S. D. Wang, D. Qiao, and S. S. Lau, Appl. Phys. Lett. 71, 2794 (1997).

${ }^{31}$ M. J. Manfra, L. N. Pfeiffer, K. W. West, H. L. Stormer, K. W. Baldwin, J. W. P. Hsu, D. V. Lang, and R. J. Molnar, Appl. Phys. Lett. 77, 2888 (2000). 